\title{
Reassessment of Maintenance and Energy Uncoupling in the Growth of Azotobacter vinelandii
}

\author{
By S. NAGAI AND S. AIBA \\ Institute of Applied Microbiology, University of Tokyo, Tokyo, Japan
}

(Received 7 February 1972; revised 24 July 1972)

\section{SUMMAR Y}

Growth yields of Azotobacter vinelandii from carbon source and oxygen were reassessed to define more clearly the terms, maintenance and true growth yield.

In oxygen-limited chemostat cultures, the maintenance coefficients, $m$ (mmol glucose $/ \mathrm{mg}$ bacteria/h) and $m_{0}\left(\mathrm{mmol} \mathrm{O}_{2} / \mathrm{mg}\right.$ bacteria/h $)$ were $8 \times 10^{-4}$ and $5.5 \times \mathrm{IO}^{-3}$; i.e. $6 m \simeq m_{0}$. This relationship between $m$ and $m_{o}$ explains the perfect oxidation of carbohydrate (glucose) by maintenance metabolism. Values of the true growth yield, $Y_{\mathrm{G}}\left(\mathrm{mg}\right.$ bacteria/mmol glucose) and $Y_{\mathrm{GO}}\left(\mathrm{mg}\right.$ bacteria $/ \mathrm{mmol} \mathrm{O}_{2}$ ) were 46 and 13 ; these values were lower than those recorded for other micro-organisms.

In glucose-limited chemostat cultures, fairly high values of $m$ and $m_{o}$ were observed and in addition, negative values of $Y_{G}$ and $Y_{G O}$ were obtained. Energyuncoupled growth could account for these negative values.

\section{INTRODUCTION}

From a mass balance of energy substrate, Pirt (I965) subdivided the total rate of substrate utilization into the rate for cellular maintenance and that for cell growth, i.e.

$$
\frac{1}{Y_{x / s}}=\frac{m}{\mu_{x}}+\frac{\mathbf{I}}{Y_{\mathrm{G}}}
$$

where $Y_{x / s}=\mathrm{d} X /-\mathrm{d} S$, total growth yield (mg bacteria/mmol glucose); $\mu_{x}=(\mathrm{I} / X)(\mathrm{d} X / \mathrm{d} t)$ specific growth rate $\left(\mathrm{h}^{-1}\right) ; m=$ maintenance coefficient $(\mathrm{mmol}$ glucose/mg bacteria/h); $Y_{\mathrm{G}}=$ true growth yield (g bacteria/mol glucose). Marr, Nilson \& Clark (1963) introduced originally the specific maintenance rate, $a\left(\mathrm{~h}^{-1}\right)$, and derived the following equation:

$$
\frac{\mathrm{I}}{Y_{x i s}}=\frac{a}{Y_{\max }} \frac{\mathrm{I}}{\mu_{x}}+\frac{\mathrm{I}}{Y_{\max }} \text {. }
$$

If the values of $m$ and $Y_{G}$ in equation (I) or those of $a$ and $Y_{\max }$ in equation (I) are constant, a linear correlation should be obtained between the reciprocals of $Y_{x / s}$ and $\mu_{x}$. Indeed, using chemostat cultures, Marr et al. (1963), Pirt (1965) and other workers verified experimentally equation (I) or (I)' with respect to Escherichia coli (Marr et al. I963; Schulze \& Lipe, 1964), Aerobacter aerogenes, A. cloacae (Pirt, 1965) and Penicillium chrysogenum (Righelato, Trinci, Pirt \& Peat, 1968).

However, some exceptions, apparently contradictory to equation (I) or equation (I)', must be mentioned. First, Pirt (I965) pointed out that the relationship between the reciprocals of $Y_{x / s}$ and $\mu_{x}$ for rumen bacteria (Hobson, 1965) deviated from the linear relationship. Secondly, when a glucose-limited chemostat culture of Azotobacter vinelandii was disrupted by suddenly changing the glucose concentration in order to check whether or not equation (I) holds true even in the unsteady state accompanying the disruption, the reciprocal plot resulted in the negative value of $Y_{G}$; a preliminary assumption that $Y_{\mathrm{G}}$ was a hyperbolic 
function of $\mu_{x}$ resolved this inconsistency (Nagai, Nishizawa, Endo \& Aiba, 1968), but there are other possible explanations.

The purpose of this work is to elaborate the true growth yield, $Y_{\mathrm{G}}$, and the maintenance coefficient, $m$, from mass balance relationships for carbon and oxygen such that a clearer definition of the terms $\left(Y_{\mathrm{a}}\right.$ and $m$ ) applicable to organisms other than Azotobacter vinelandii can be obtained.

\section{METHODS}

Bacterial strain and culture conditions. Azotobacter vinelandii IAM 1078 (ATCC9046) was grown at $30 \pm 0.5{ }^{\circ} \mathrm{C}$ in $(\mathrm{g} / \mathrm{l})$ : glucose, 5 or $8 ; \mathrm{KH}_{2} \mathrm{PO}_{4}, 0.2 ; \mathrm{K}_{2} \mathrm{HPO}_{4}, 0.8 ; \mathrm{MgSO}_{4} \cdot 7 \mathrm{H}_{2} \mathrm{O}$, 0.2 ; sodium citrate, $0.05 ; \mathrm{FeSO}_{4} \cdot 7 \mathrm{H}_{2} \mathrm{O}$, 0.005; $\mathrm{Fe}_{2}\left(\mathrm{SO}_{4}\right)_{3} \cdot 3 \mathrm{H}_{2} \mathrm{O}, 0.005 ; \mathrm{Na}_{2} \mathrm{MoO}_{4} \cdot 2 \mathrm{H}_{2} \mathrm{O}$, $0.00 \mathrm{I} ; \mathrm{CaCl}_{2} .2 \mathrm{H}_{2} \mathrm{O}, 0.0 \mathrm{I} ; \mathrm{pH} 7 \cdot 0$ to $7 \cdot 2$. The fermenter vessel used was 301 (working volume I 5 l) and aeration rate was fixed at $9 \mathrm{l} / \mathrm{min}$ throughout. Glucose-limited and oxygen-limited chemostat cultures could be established by controlling the agitation speed in each run. The bacterial mass, residual glucose and respiration rate in each chemostat culture were measured by standard methods described elsewhere (Nagai, Nishizawa \& Aiba, I969).

\section{RESULTS AND DISCUSSION}

Energy-balance equations for cell growth. Equation (I) can be rearranged as follows:

$$
\nu=m+\mu_{x} / Y_{\mathrm{G}},
$$

where $v=(\mathrm{I} / X)(-\mathrm{d} S / \mathrm{d} t)$, specific rate of glucose utilization (mmol glucose $/ \mathrm{mg}$ bacteria $/ \mathrm{h})$. Assuming that carbon dioxide and water are the only metabolites other than the bacteria, Johnson (1964), presented the following balance equation which deals with oxygen requirement:

$$
A v=B \mu_{x}+Q_{0_{2}}
$$

where $A$ is the amount of oxygen required for combustion of glucose (or glycerol) (mmol $\mathrm{O}_{2} / \mathrm{mmol}$ glucose), $B$ is the amount of oxygen required for combustion of cells (mmol $\mathrm{O}_{2} / \mathrm{mg}$ bacteria) $=0.042$ (Johnson, 1964 ), and $Q_{\mathrm{O}_{2}}$ is the specific rate of respiration (mmol $\mathrm{O}_{2} / \mathrm{mg}$ bacteria/h). In the light of mass balance, equation (3) is essentially along the same line of equation (I) or (I)'. Av on the left-hand side of equation (3) is the amount of oxygen required for a complete combustion of substrate consumed, while the first and second terms on the right-hand side of the equation represent the amount of oxygen needed for a complete combustion of bacteria synthesized and that amount required for the bacterial synthesis, respectively.

Payne (1970) employed total energy in place of oxygen requirement mentioned previously in equation (3), and from the concept of energy conservation he subdivided the total energy derivable from the medium $(\propto A \nu)$ into the energy responsible for the bacterial growth $\left(\propto B \mu_{x}\right)$ and that expended in catabolism $\left(\propto Q_{\mathrm{o}_{2}}\right)$.

Analogous to equation (I) or (2), the specific respiration rate can be described in terms of maintenance and growth (Herbert, 1958, Schulze \& Lipe, 1964; Pirt, 1965; Righelato et al. 1968; van Uden, 1968; Harrison \& Loveless, 1971):

or

$$
Q_{\mathrm{o}_{2}}=\left(Q_{\mathrm{O}_{2}}\right)_{m}+\left(Q_{\mathrm{O}_{2}}\right)_{\mathrm{G}}
$$

$$
Q_{\mathrm{O}_{2}}=m_{o}+\frac{\mathrm{I}}{Y_{\mathrm{Go}}} \mu_{x}
$$




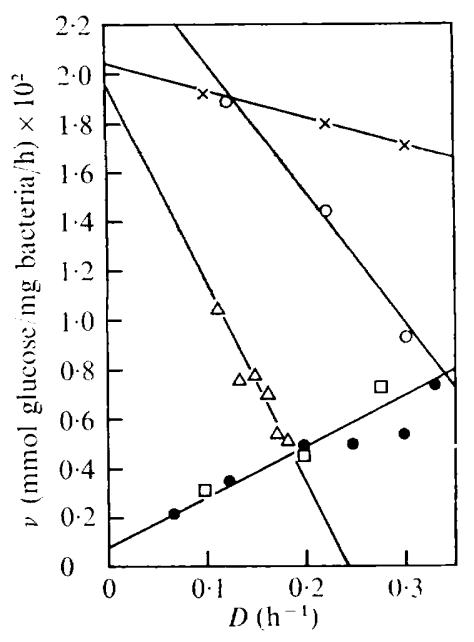

Fig. I

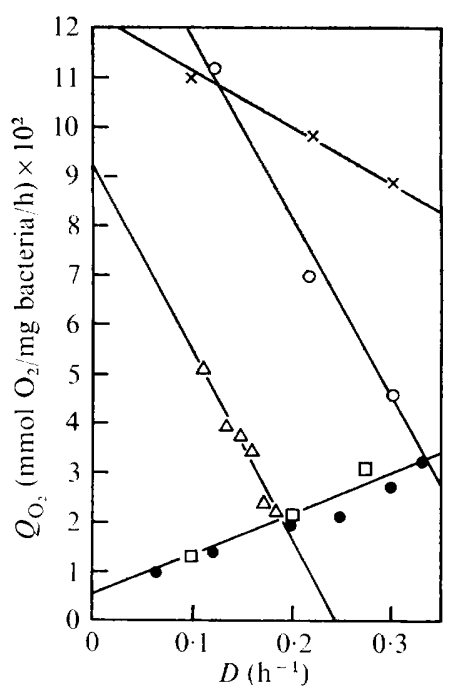

Fig. 2

Fig. I. Specific rate of glucose consumption against dilution rate in glucose-limited and oxygenlimited chemostat cultures of Azotobacter vinelandii. O, Oxygen-limited at $240 \mathrm{rev} . / \mathrm{min}, S_{o}=45$; $\square$, oxygen-limited at $340 \mathrm{rev} . / \mathrm{min}, S_{o}=44 ; \triangle$, glucose-limited at $540 \mathrm{rev} . / \mathrm{min}, S_{o}=43$; $O$, glucose-limited at $780 \mathrm{rev} . / \mathrm{min}, S_{o}=44 ; \times$, glucose-limited at $780 \mathrm{rev} . / \mathrm{min}, S_{o}=27$; $S_{o}$, glucose concentration in fresh medium ( $\left.\mathrm{mmol} / \mathrm{l}\right)$; rev./min, agitation speed.

Fig. 2. Specific rate of respiration against dilution rate in glucose-limited and oxygen-limited chemostat cultures of Azotobacter vinelandii. $\bullet, \square$, Oxygen-limited; $\triangle, \bigcirc, \times$, glucose-limited (for details see in Fig. I).

where $m_{o}$ is the maintenance coefficient for respiration $\left(\mathrm{mmol} \mathrm{O}_{2} / \mathrm{mg}\right.$ bacteria/h) and $Y_{\mathrm{Go}}$ is the $\mathrm{d} X /\left(\mathrm{dO}_{2}\right)_{\mathrm{G}}$, true growth yield for oxygen $\left(\mathrm{mg}\right.$ bacteria $\left./ \mathrm{mmol} \mathrm{O}_{2}\right)$. From equations (3) and (5),

From equations (2) and (6),

$$
\nu=\frac{m_{o}}{A}+\frac{\mathrm{I}}{A}\left(B+\frac{\mathrm{I}}{Y_{\mathrm{ao}}}\right) \mu_{x}
$$

$$
\begin{gathered}
m=\frac{m_{o}}{A}, \\
\frac{1}{Y_{G}}=\frac{\mathrm{I}}{A}\left(B+\frac{\mathrm{I}}{Y_{\mathrm{GO}}}\right) .
\end{gathered}
$$

Now, the maintenance coefficient, $m_{\theta}$, appearing in equation (5) is interpreted as that corresponding to the complete oxidation of glucose, while the specific rate of glucose metabolized for growth, $\mu_{x} / Y_{\mathrm{G}}$, in equation (2) is re-interpreted as a sum of that rate incorporated into the cellular material, $B \mu_{x} / A$, and another expended in catabolism, $\mu_{x} / A Y_{\mathrm{G} 0}$.

The experimental results of glucose- and oxygen-limited chemostat cultures are shown in Fig. I and 2 (cf. equations (2) and (5)). If the values of $m, m_{0}, Y_{\mathrm{G}}$ and $Y_{\mathrm{Go}}$ are constant respectively, linear relationships are expected between $\nu$ and $\mu_{x}(=D)$, or $Q_{\mathrm{O}_{2}}$ and $\mu_{x}(=D)$. For oxygen-limited chemostat cultures, positive values of $\left(m, Y_{\mathrm{G}} ; m_{o}, Y_{\mathrm{G} 0}\right)$ were obtained. Several workers also presented this kind of correlation (Herbert, 1958; Schulze \& Lipe, 1964; Pirt, I965; Righelato et al. 1968; van Uden, 1968). However, an apparently unacceptable result is noted from Fig. I and 2 for the glucose-limited chemostat culture; large values 
Table I. True growth yields and maintenance coefficients for various organisms

\begin{tabular}{|c|c|c|c|c|c|c|c|c|c|}
\hline Organism & $\begin{array}{l}\text { Limiting } \\
\text { factor }\end{array}$ & Substrate & $m$ & $m_{o}$ & $m_{o}^{*}$ & $Y_{G}$ & $Y_{G}^{*}$ & $Y_{\mathrm{GO}}$ & Reference \\
\hline $\begin{array}{l}\text { Aerobacter } \\
\quad \text { aerogenes }\end{array}$ & Glycerol & Glycerol & 0.83 & $3 \cdot 4$ & $2 \cdot 9$ & $5 \mathrm{I}$ & 47 & 30 & Herbert (1958) \\
\hline A. clocae & Glucose & Glucose & 0.5 & - & 3.0 & 79 & - & - & Pirt (1965) \\
\hline $\begin{array}{r}\text { Azotobacter } \\
\text { vinelandii }\end{array}$ & Oxygen & Glucose & 0.8 & $5 \cdot 5$ & $4 \cdot 8$ & 46 & 50 & 13 & This work \\
\hline $\begin{array}{l}\text { Escherichia } \\
\quad \text { coli }\end{array}$ & Glucose & Glucose & 0.3 & 0.5 & 1.8 & 95 & 90 & $4 I \cdot 5$ & $\begin{array}{l}\text { Schulze \& Lipe } \\
\text { (1964) }\end{array}$ \\
\hline $\begin{array}{l}\text { Penicillium } \\
\text { chrysogenum }\end{array}$ & Glucose & Glucose & 0.12 & 0.74 & 0.72 & $8 \mathrm{I}$ & 97 & 50 & $\begin{array}{l}\text { Righelato et al. } \\
\quad(1968)\end{array}$ \\
\hline $\begin{array}{c}\text { Saccharomyces } \\
\text { cerevisiae }\end{array}$ & Glucose & Glucose & 0.08 & 0.60 & 0.48 & 9I & 85 & $34 \cdot 5$ & $\begin{array}{l}\text { von Meyenburg } \\
\text { (I969) }\end{array}$ \\
\hline
\end{tabular}

Unit: $m$ (mmol substrate $/ \mathrm{g}$ bacteria $/ \mathrm{h}) ; m_{0}\left(\mathrm{mmol} \mathrm{O}_{2} / \mathrm{g}\right.$ bacteria $\left./ \mathrm{h}\right) ; Y_{\mathrm{G}}(\mathrm{g}$ bacteria/mol substrate); $Y_{\text {Go }}\left(\mathrm{g}\right.$ bacteria $/ \mathrm{mol} \mathrm{O}_{2}$ ).

* Value calculated by equation (7) or (8), $A=6$ ( $\mathrm{mol} \mathrm{O}_{2} / \mathrm{mol}$ glucose) or 3.5 for glycerol, $B=4 \mathrm{I} \cdot 7$ ( $\mathrm{mmol} \mathrm{O}_{2} / \mathrm{g}$ bacteria).

of $m, m_{o}$ and negative values of $Y_{G}, Y_{G 0}$. A concept of energy-uncoupled growth could resolve the unacceptable observation.

Values of $m, m_{o}, Y_{\mathrm{G}}$ and $Y_{\mathrm{GO}}$ which are assessed from Fig. I and 2 and values cited from the data published by other workers on some other organisms are summarized in Table $I$. Values of $m$ and $m_{o}$ depended on the species of organisms; fairly low values were observed with Penicillium chrysogenum and Saccharomyces cerevisiae. Except for Escherichia coli, $m_{o}^{*}$ values calculated from equation (7) are in good agreement with those observed. This agreement supports the hypothesis that maintenance metabolism results in the complete oxidation of glucose (glycerol). The fairly large difference between $m_{o}$ and $m_{o}^{*}$ for E. coli in the table might have originated from the usual procedure of $Q_{\mathrm{O}_{2}}$ measurement with a Warburg manometer, i.e. the cells were transferred from the glucose-limited chemostat culture to the manometer, thus disrupting the glucose-limited environment. On the other hand, the values for $m_{o}$ for other organisms in Table I were assessed from $Q_{\mathrm{o}_{2}}$ measurements with chemostat cultures by observing the difference in oxygen concentrations between inlet and outlet air.

Values of $Y_{\mathrm{G}}$ and $Y_{\mathrm{Go}}$ for Azotobacter vinelandii in Table I are lower than those for other organisms. This fact is ascribed to the higher energy requirement for nitrogen fixation from air in this organism. In addition to the previous agreement of $m_{o}$ between observation and calculation, another fact that $Y_{\mathrm{G}}$ values estimated directly from the measurement of $v$ with the use of equation (2) agreed favourably with $Y_{G}^{*}$ values assessed from $Q_{0_{2}}$ measurements, utilizing equation (8) justifies equation (3).

Energy-uncoupled growth. Results from anaerobic cultures suggest that $Y_{\mathrm{ATP}}$ is $10.5 \mathrm{~g}$ bacteria/mol ATP (Bauchop \& Elsden, I960; Hadjipetrou, Gerrits, Teulings \& Stouthamer, 1964). The paucity of $Y_{\text {ATP }}$ values for aerobic cultures, on the other hand, originates from the lack of information on energy yield and expenditure. However, according to Stouthamer (1962) the values of $Y_{\text {ATP }}$ for aerobically grown cells of Gluconobacter liquefaciens using various carbohydrates were also Io g bacteria/mol ATP. Hernandez \& Johnson (1967b) proposed that some factor other than ATP might have become the growth-limiting factor in an aerobic culture of Candida utilis and Saccharomyces carlsbergensis, because the value of $Y_{\mathrm{ATP}}$ estimated from the value of $Q_{\mathrm{o}_{2}}$ measured and $\mathrm{P} / \mathrm{O}$ ratio assumed was about 7; 


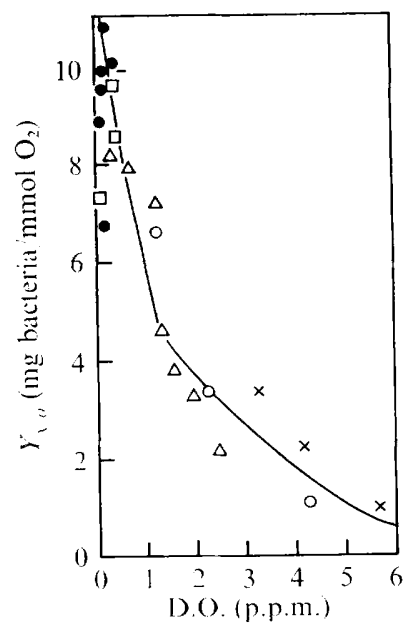

Fig. 3. Total growth yield for oxygen uptake against dissolved oxygen concentration in glucoselimited and oxygen-limited chemostat cultures of Azotobacter vinelandii. $\bullet, \square$, Oxygen-limited; $\therefore, O, \times$, glucose-limited (for details, see in Fig. I).

they suggested the possibility that some fraction of ATP synthesized might have been wasted as heat. Similar phenomena designated as energy-uncoupled growth have been observed in anaerobic cultures of Escherichia coli (Hernandez \& Johnson, 1967a) and in aerobic cultures of Desulfovibrio desulfuricans and Aerobacter aerogenes (Senez, 1962) and Klebsiella aerogenes (Harrison \& Loveless, I97I).

Before proceeding to discuss the energy-uncoupled growth of Azotobacter vinelandii it is necessary to refer briefly to the inhibitory effect of dissolved oxygen on the microbial growth of this organism, because energy-uncoupled growth is closely related to this inhibitory phenomenon (Phillips \& Johnson, I96I; Ackrell \& Jones, I97I ; Nagai, Nishizawa, Onodera \& Aiba, 1971). Phillips \& Johnson (1961) and Nagai et al. (197I) pointed out that an oxygenwasting system functions when dissolved oxygen exceeds a critical level. From the analysis of enzymes responsible for growth in glucose-limited chemostat culture, Nagai et al. (I97I) showed that the oxygen-wasting system became predominant at high oxygen concentration.

Total growth yields for oxygen, $Y_{x / o}\left(\mathrm{mg}\right.$ bacteria/mmol $\left.\mathrm{O}_{2}\right)$ obtained from glucose- and oxygen-limited chemostat cultures are correlated with dissolved oxygen concentration (Fig. 3), regardless of the limiting conditions.

We now develop a hypothesis which explains the negative yield constants illustrated in Fig. I and 2. Let $Q_{\mathrm{o}_{2}}$ be subdivided into the following terms:

$$
Q_{\mathrm{o}_{2}}=\left(Q_{\mathrm{o}_{2}}\right)_{\mathrm{G}}+\left(Q_{\mathrm{o}_{2}}\right)_{U},
$$

where $\left(Q_{\mathrm{O}_{2}}\right)_{U}$ is the specific rate of respiration relevant to energy-uncoupling $\left(\mathrm{mmol} \mathrm{O}_{2} / \mathrm{mg}\right.$ bacteria/h). The second term, $\left(Q_{O_{2}}\right)_{v}$, on the right-hand side of equation (9), incorporates the term, $\left(Q_{\mathrm{O}_{2}}\right)_{m}$, attributable to maintenance, and another term due to energy loss. By replacing $\left(Q_{\mathrm{O}_{2}}\right)_{m}$ with $\left(Q_{\mathrm{o}_{2}}\right)_{U}$ the abnormally high values for $m_{o}$ obtained by plotting the data from glucose-limited chemostat cultures of Azotobacter vinelandii according to equation (5) can be explained. When energy loss can be disregarded, the use of $\left(Q_{\mathrm{O}_{2}}\right)_{v}$ in exchange for $\left(Q_{\mathrm{O}_{2}}\right)_{m}$ is not always required. 


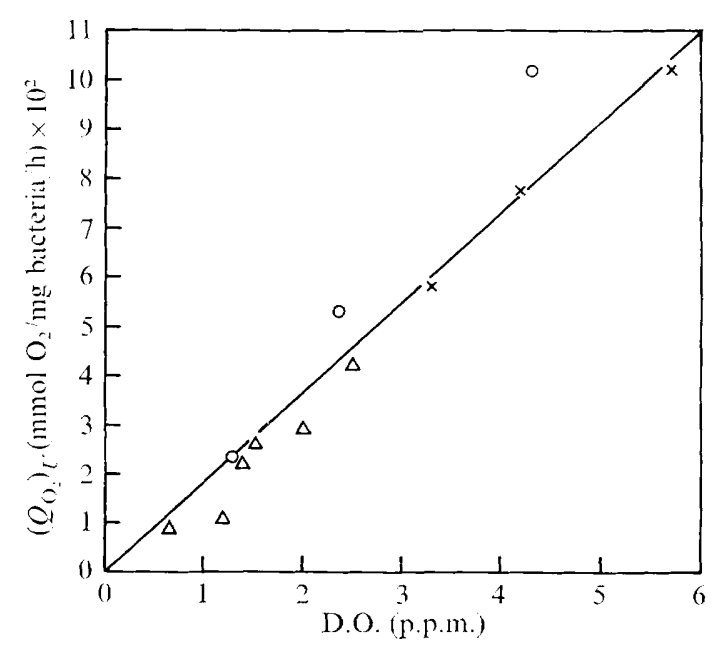

Fig. 4. Oxygen waste in Azotobacter vinelandii affected by dissolved oxygen concentration in glucose-limited chemostat cultures (for symbols, see in Fig. I).

From equations (5) and (9)

$$
\begin{aligned}
\left(Q_{\mathrm{o}_{2}}\right)_{U} & =Q_{\mathrm{O}_{2}}-\left(Q_{\mathrm{o}_{2}}\right)_{\mathrm{G}} \\
& =Q_{\mathrm{O}_{2}}-\frac{\mathrm{I}}{Y_{\mathrm{Go}}} \mu_{x}
\end{aligned}
$$

It therefore becomes possible to evaluate $\left(Q_{\mathrm{o}_{2}}\right)_{U}$ from the terms on the right-hand side of equation (IO), if it is assumed that the value of $Y_{\mathrm{GO}}$ from the energy-coupled (oxygenlimited) growth listed in the table for Azotobacter vinelandii can also be used for glucoselimited chemostat culture. The values of $\left(Q_{\mathrm{O}_{2}}\right)_{U}$ estimated in this way are plotted against dissolved oxygen concentration in Fig. 4. In spite of the difference in experimental details for glucose-limited chemostat cultures, it is noted from Fig. 4 that the specific rate of respiration relevant to energy-uncoupling increased almost linearly with the increase in dissolved oxygen concentration. Thus to a close approximation:

$$
\left(Q_{\mathrm{o}_{2}}\right)_{U}=U(\text { D.O. }) \text {, }
$$

where $U=$ proportionality constant, D.O. = dissolved oxygen concentration (p.p.m.).

In Fig. $5 a$ dissolved oxygen concentration, D.O., and total rate of $\mathrm{O}_{2}$ uptake, $Q_{\mathrm{O}_{2}} X$ $\left(\mathrm{mmol} \mathrm{O}_{2} / \mathrm{ml}\right.$ culture $/ \mathrm{h}$ ), are plotted against dilution rate, $D\left(\mathrm{~h}^{-1}\right)$. It is noted from the figure that the increase in dilution rate, $D$, was accompanied by an appreciable increase in $Q_{\mathrm{o}_{2}} X$, principally emerging from the increase in $X(\mathrm{mg}$ bacteria/ml culture). It therefore seems that an increase in $Q_{\mathrm{o}_{2}} X$ resulted in the decrease in dissolved oxygen concentration in each run, provided that the aeration rate and the rotation speed of the impeller were kept constant.

If a straight line is drawn through each set of the data points in Fig. 5(b), then

$$
\text { D.O. }=E+F \mu_{x} \text {, }
$$

where $E=$ intersection of straight line with ordinate; $F=$ slope of straight line.

Although the values of $E$ and $F$ have no particular significance from a biological viewpoint, the observations on $Q_{\mathrm{O}_{2}} X$ versus $D$ referred to above underlie the negative values of $F$ for the glucose-limited chemostat cultures. In fact, another analysis (Nagai \& Aiba, 1972), 

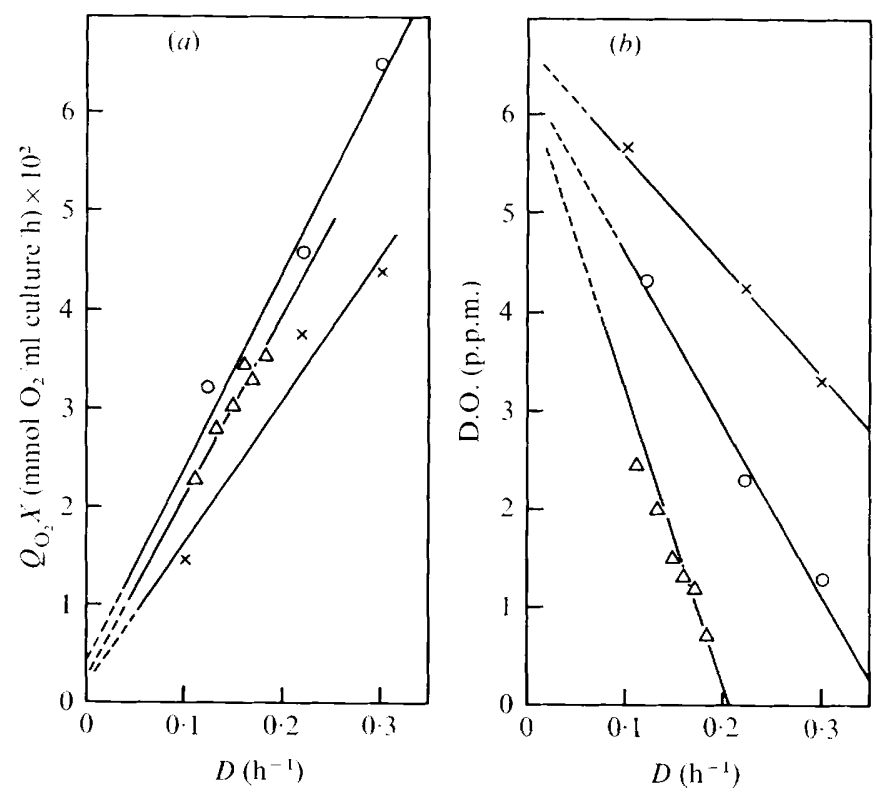

Fig. 5 (a) Oxygen requirement of culture ( $\mathrm{mmol} \mathrm{O}_{2} / \mathrm{ml}$ culture $/ \mathrm{h}$ ), and $(b)$ dissolved oxygen concentration against dilution rate in glucose-limited chemostat cultures of Azotobacter vinelandii (for symbols, see in Fig. I).

utilizing activities of aldolase and glyceraldehyde-3-phosphate dehydrogenase as key parameters in the branched enzymatic kinetics (Waley, 1964), showed the decrease of D.O. as a hyperbolic function of $\mu_{x}$. The fact that the increase in dilution rate was followed by a sharp decrease of D.O. as shown in Fig. $5(b)$ was either represented empirically by equation (I2) or supported theoretically by the more sophisticated model.

Equations (I I) and (I 2) give:

$$
\left(Q_{\mathrm{o}_{2}}\right)_{U}=U E+U F \mu_{x}
$$

Further, equations (I0) and (r3) yield

$$
Q_{\mathrm{o}_{2}}=U E+\left(U F+\frac{\mathrm{x}}{Y_{\mathrm{go}}}\right) \mu_{x} \text {. }
$$

It is evident from equations (5) and ( 14 ) that the terms, $m_{o}$ and $Y_{\mathrm{GO}}^{-1}$ observed with glucoselimited chemostat cultures correspond to $U E$ and $\left(U F+\left(\mathrm{I} / Y_{\mathrm{GO}}\right)\right)$ respectively. The values $\left(U F+\left(\mathrm{I} / Y_{\mathrm{GO}}\right)\right)$ or $Y_{\mathrm{GO}}^{-1}$ measured for the glucose-limited chemostat cultures (see Fig. 2) are negative because the negative values of $U F$ for the glucose-limited chemostat culture overweighed the value of $Y_{\mathrm{GO}}^{-1}$ in equation (14): needless to say, the value of $Y_{\mathrm{Go}}$ for the true growth yield should be positive at all times.

Another contradictory phenomenon, the higher values of $m$ and negative values of $Y_{G}$ for the glucose-limited chemostat cultures (see equation (2) and Fig. I), could also be reinterpreted by the following equation obtainable from equations (3) and (I4).

$$
\nu=\frac{U F}{A}+\frac{\mathrm{I}}{A}\left(U F+\frac{\mathrm{I}}{Y_{\mathrm{Go}}}+B\right) \mu_{x} .
$$

The negative values of $Y_{\mathrm{G}}\left(=\left(U F+\left(\mathrm{I} / Y_{\mathrm{GO}}\right)+B\right)^{-1}\right)$ could be explained by the fact that $U F$ values (negative) overweighed positive values of $\left(\mathrm{I} / Y_{\mathrm{Go}}\right)+B$. 


\section{REFERENCES}

ACKrell, B. A. C. \& Jones, C. W. (I97I). The respiratory system of Azotobacter vinelandii. 2. Oxygen effects. European Journal of Biochemistry 20, 29-35.

Bauchop, T. \& Elsden, S. R. (1960). The growth of micro-organisms in relation to their energy supply. Journal of General Microbiology 23, 457-469.

Hadjpetrou, L. P., Gerrits, J. P., Teulings, F. A. G. \& Stouthamer, A. H. (I964). Relation between energy production and growth of Aerobacter aerogenes. Journal of General Microbiology 36, I $39-150$.

Harrison, D. E. F. \& Loveless, J. E. (197I). The effect of growth conditions on respiratory activity and growth efficiency in facultative anaerobes grown in chemostat culture. Journal of General Microbiology 68, 35-43.

Herbert, D. (1958). Some principles of continuous culture. Symposium of the International Congress of Microbiology, no. 6, pp. 38I-396.

Hernandez, E. \& Johnson, M. J. ( $1967 a$ ). Anaerobic growth yield of Aerobacter cloacae and Escherichia coli. Journal of Bacteriology 94, 99 I-995.

Hernandez, E. \& Johnson, M. J. (I967b). Energy supply and cell yield in aerobically grown microorganisms. Journal of Bacteriology 94, 996-100 I.

Hobson, P. N. (1965). Continuous culture of some anaerobic and facultatively anaerobic rumen bacteria. Journal of General Microbiology 38, 167-180.

JoHnSON, M. J. (1964). Utilisation of hydrocarbons by microorganisms. Chemistry and Industry, I532I 537 .

Marr, A. G., Nilson, E. H. \& Clark, D. J. (1963). The maintenance requirement of Escherichia coli. Annals of the New York Academy of Sciences 102, 536-548.

von Meyenburg, H. K. (1969). Energetics of the budding cycle of Saccharomyces cerevisiae during glucose limited aerobic growth. Archiv für Mikrobiologie 66, 289-303.

NAGAI, S. \& AiBa, S. (1972). Kinetics of yield factor as affected by dissolved oxygen in a chemostat culture of Azotobacter vinelandii. Symposium of International Fermentation, no. 4 (in the press).

NAGA, S., Nishizawa, Y. \& Aiba, S. (1969). Energetics of growth of Azotobacter vinelandii in a glucoselimited chemostat culture. Journal of General Microbiology 59, 163-I 69.

Nagai, S., Nishizawa, Y., Endo, I. \& Aiba, S. (1968). A sophisticated analysis of yield factors for Azotobacter vinelandii. Journal of Fermentation Technology 46, 725-732.

NaGai, S., Nishizawa, Y., Onodera, M. \& Aiba, S. (I97I). Effect of dissolved oxygen on growth yield and aldolase activity in chemostat culture of Azotobacter vinelandii. Journal of General Microbiology 66, $197-203$.

PAYNe, W. J. ( I970). Energy yield and growth of heterotrophs. Annual Review of Microbiology 24, 17-5I.

Phillips, D. H. \& Johnson, M. J. (1961). Aeration in fermentations. Journal of Biochemical and Microbiological Technology and Engineering 3, 277-309.

PIRT, S. J. (I965). The maintenance energy of bacteria in growing cultures. Proceedings of The Royal Society B I63, 224-23I.

Righelato, R. C. R., Trinci, A. P. J., Pirt, S. J. \& Peat, A. (I968). The influence of maintenance energy and growth rate on the metabolic activity, morphology and conidiation of Penicillium chrysogenum. Journal of General Microbiology 50, 399-4I 2.

SChultze, K. L. \& LiPE, R. S. (I964). Relationship between substrate concentration, growth rate, and respiration rate of Escherichia coli in continuous culture. Archiv für Mikrobiologie 48, I-20.

SENEZ, J. C. (I962). Some considerations on the energetics of bacterial growth. Bacteriological Reviews $\mathbf{2 6}$, 95-107.

Stouthamer, A. H. (1962). Energy production in Gluconobacter liquefaciens. Biochimica et biophysica acta 56, I9-32.

VAN UDEN, N. (1968). Yield and maintenance analysis in the chemostat; a tool for metabolic studies of growing cells. Archiv für Mikrobiologie 62, 34-40.

WALEY, S. G. (I964). A note of the kinetics of multi-enzyme system. Biochemical Journal 9r, 5I4-5I 7. 